\title{
PEMBERDAYAAN KELOMPOK INFORMASI MASYARAKAT SEBAGAI SALURAN BERBAGI INFORMASI PENANGKAPAN TELUR IKAN TERBANG DI KABUPATEN MAJENE DAN POLMAN
}

\author{
The Empowerment of Community Information Groups \\ as the Channels of Various Information on the Catching of Flying Fish Eggs \\ in Majene Regency and Polewali Mandar Regency
}

\author{
${ }^{1}$ Abdillah Makkarana, ${ }^{2}$ Hafied Cangara, ${ }^{3}$ Syamsu Alam Ali \\ ${ }^{1}$ Ilmu Komunikasi, Fakultas Ilmu Sosial dan Ilmu Politik, \\ Universitas Hasanuddin, Makassar (abdiq25@gmail.com) \\ ${ }^{2}$ Komunikasi, Fakultas Ilmu Sosial dan Ilmu Politik, \\ Universitas Hasanuddin, Makassar (cangara hafied@gmail .com) \\ ${ }^{3}$ Manajemen Sumberdaya Perairan, Fakultas Ilmu Kelautan dan Perikanan, \\ Universitas Hasanuddin, Makassar (syamsualam.ali@gmail.com)
}

\begin{abstract}
ABSTRAK
Keterbatasan akses dan kemampuan masyarakat dalam memanfaatkan informasi dan kesenjangan informasi dikalangan masyarakat pedesaan.Penelitian ini bertujuan untuk mengetahui (1) Peranan Kelompok Informasi Masyarakat (KIM), (2) bentuk informasi yang mereka bagi diantara para nelayan penangkap telur ikan terbang serta (3) startegi pemerintah dalam memberdayakan Kelompok Infomasi Masyarakat di Kelurahan Mosso Kabupaten Majene dan Desa Pambusuang Kabupaten Polman.Penelitian ini merupakan penelitian deskriptif kualitatif dengan pendekatan studi kasus yang dilakukan pada KIM di Kelurahan Mosso Kabupaten Majene dan desa Pambusuang Kabupaten Polewali Mandar, Provinsi Sulawesi Barat. Data penelitian ini diperoleh dari hasil observasi dan wawancara mendalam oleh informan atau narasumber.Dari hasil penelitian diketahui bahwa Peran Kelompok Informasi Masyarkat (KIM) hingga saat ini belum berjalan dengan baik dan dari Kelompok Informasi Masyarakat memiliki peran yang dapat dikelompokan kedalam lima kegiatan, yaitu: sebagai fasilitator bagi masyarakat, sebagai mitra pemerintah daerah, sebagai penyerap dan penyalur aspirasi masyarakat, dan sebagai terminal informasi bagi masyarakat. Walaupun peran menjadi mitra pemerintah dalam menyebarluaskan informasi belum berjalan dengan baik, masih berbentuk penerapan dalam menyebarkan informasi melalui tatap muka untuk saat ini, hal ini yang perlu dibenahi dan mesti diperbaiki dari segi sistem komunikasi antara pemerintah desa/kelurahan terhadap kelompok informasi masyarakat (KIM), dan koordinasi terhadap pemerintah daerah dan pemerintah desa.
\end{abstract}

Kata kunci: Akses Informasi, Kelompok Informasi Masyarakat, Pemberdayaan Kelompok

\begin{abstract}
Limited access and the ability of communities in using information and gap information in village's communites.The aims of the research were to find out (1) the role of Community Information Groups, (2) the types of information the fishermen of flying fish egg share, (3) the governments' strategies in the empowerment of Community Information Groups in Mosso Village of Majene Regency and Pambusuang Village of Polewali Mandar Regency. The research was a descriptive qualitative analysis with the case study approach done to Community Information Groups in Mosso Village of Majene Regency and Pambusuang Village of Polewali Mandar Regency, West Sulawesi Province. The data were obtained through observation and in-depth interview to the informants. The result of the research indicate that the role of Community Information Groups does not run well. The roleof these groups are divided into five activities, i.e. facilitators for community, partners for local government, absorbing and channeling community's aspirations, and information terminal for community. The role as the partner of local government in dessiminating information through face to face at present.
\end{abstract}


Communication system between village government and Community Information Groups and coordination with local government and village government needs addressing and improving.

Keywords: information access, Community Information Group, group empowerment.

\section{PENDAHULUAN}

Kebutuhan masyarakat untuk mendapatkan informasi saat ini mengalami perkembangan yang pesat, mulai dari masyarakat tingkat bawah sampai tingkat atas, terlebih setelah bergulirnya era reformasi tahun 1998. Beragam dan kompleksnya informasi yang beredar di tengah masyarakat merupakan sebab dari tuntutan masyarakat yang haus akan kebenaran dan nilai suatu informasi. Ruslan (2002), mengatakan bahwa informasi diperlukan untuk mengurangi ketidakpastian dalam suatu sistem komunikasi di suatu lembaga atau organisasi.Namun, kondisi sebagian masyarakat yang belum memiliki kemampuan memadai untuk menelaah muatan informasi, baik karena faktor sosial, edukatif, ekonomis maupun kultural. Selain itu, keterbatasan akses dan kemampuan masyarakat dalam memanfaatkan informasi dan kesenjangan informasi dikalangan masyarakat pedesaan.

Kelompok Informasi Masyarakat (KIM) merupakan lembaga layanan publik yang dibentuk dan dikelola dari, oleh dan untuk masyarakat yang berorientasi pada layanan informasi dan pemberdayaan masyarakat sesuai dengan kebutuhannya (Direktorat Kelembagaan Komunikasi Sosial, 2008). 3 kegiatan pokok yang dilakukan dalam KIM, yaitu mengakses informasi, mengolah informasi dan menyebarluaskan informasi. KIM berperan dalam memperlancar kontribusi dan distribusi informasi kepada masyarakat, selain itu KIM sebagai mediator antara masyarakat dan pemerintah dalam penyebaran informasi dan penyerapan aspirasi.

Indonesia yang sebagian besar wilayahnya terdiri dari lautan dan memiliki potensi kelautan cukup besar, seharusnya mampu mensejahterakan kehidupan masyarakat nelayan yang menggantungkan hidup pada potensi kelautan (maritim) tersebut. Usaha penangkapan ikan terbang dilakukan masyarakat nelayan di perairan Selat Makassar dan Laut Flores adalah merupakan salah satu sumber mata pencaharian masyarakat (Ali, 2005). Ikan terbang (Cypselurus spp) merupakan salah satu potensi perikanan pelagis kecil di Indonesia dengan pemanfaatannya cukup besar terutama di perairan Kawasan Timur Indonesia, sehingga merupakan salah satu bagian kegiatan penangkapan ikan bagi nelayan yang cukup penting. Ikan terbang telah dikenal dan dikonsumsi oleh sebagian masyarakat Indonesia, khususnya di Sulawesi Selatan dan Sulawesi Barat. Ikan ini dikenal dengan berbagai nama lokal di beberapa daerah seperti: ikan tuing-tuing (Makassar), torani (Bugis) dan caeqeng (Mandar). Pelras (2006), menilai bahwa sebenarnya leluhur orang Mandarlah yang ulung melaut bukan orang Bugis seperti pendapat banyak orang.

Berdasarkan data pada Dinas Perindustrian dan Perdagangan Provinsi Sulawesi Selatan Tahun 2014 mengenai realisasi ekspor Sulawesi Selatan berdasarkan penerbitan Certificate of Origin (COO) atau Surat Keterangan Asal (SKA), sektor pertanian jenis Komoditi telur ikan terbang menempati urutan kelima setelah komoditi Rumput laut, biji kakao, udang segar dan biji kopi.Ekspor komoditi Telur Ikan Terbang Sulawesi Selatan pada triwulan keempat (Januari-Desember) 2014 sebesar US\$ 17.619.816 dengan volume sebesar 893 ton, sedangkan pada tahun 2013 periode yang sama nilai sebesar US\$ 13.675.500 dengan volume sebanyak 615ton. Halmana terdapat peningkatan nilai sebesar US\$ 3.944.316 atau meningkat 28,84 persen yang disertai peningkatan volume sebesar 278 ton atau meningkat 45,20 persen.

Tujuan penelitian ini agar masyarakat mengetahui peran dan fungsi KIM dalam berbagi informasi dikalangan masyarakat nelayan sehingga masyarakat lebih mengetahui pentingnya informasi dan mengetahui strategi pemerintah dalam memberdayakan KIM di daerah.

\section{BAHAN DAN METODE}

Penelitian ini menggunakan paradigma penelitian deskriptif kualitatif dengan pendekatan studi kasus dimana peneliti berusaha mendeskripsikan hasil observasi 
pada objek penelitian yaitu mengadakan pengamatan langsung ke lokasi penelitian

Moleong (2006), menjelasan bahwa dalam studi kasus hendaknya peneliti berusaha menguji unit atau individu secara mendalarn.Para peneliti berusaha menernukan sernua variabel yang penting. Berdasarkan batasan tersebut dapat dipahami bahwa batasan studi kasus meliputi: (1) sasaran penelitiannya dapat berupa manusia, peristiwa, latar, dan dokumen; (2) sasaran-sasaran tersebut ditelaah secara mendalam sebagai suatu totalitas sesuai dengan latar atau konteksnya masing-masing dengan maksud untuk mernahami berbagai kaitan yang ada di antara variabel-variabelnya.Pendekatan ini dapat menguraikan mengenai peran KIM dalam berbagi informasi, studi kasus penangkapan telur ikan terbang di kelurahan Mosso Kabupaten Majene dan desa Pambusuang Kabupaten Polewali Mandar.

\section{Lokasi dan Rancangan Penelitian}

Proses penelitian atau pengumpulan data dan informasi terhadap informan dilakukan melalui observasi langsung pada lokasi di kelurahan Mosso Kabupaten Majene dan desa Pambusuang Kabupaten Polewali Mandar.Wawancara dengan informan di Kabid Pelayanan Media Kominfo Kabupaten Majene dan Staf Kominfo Kabupaten Polewali Mandar, Kabid Program perencanaan Dinas Kelautan dan Perikanan Kabupaten Polewali Mandar, dan Pengawas perikanan Dinas Kelautan dan Perikanan Kabupaten Majene serta Kelompok Informasi masyarakat di Kelurahan Mosso Kabupaten Majene dan para nelayan. Kelompok Informasi Masyarakat di Desa Pambusuang Kabupaten Polewali Mandar dan para nelayan.

\section{Sumber Data}

Jenis data yang dikumpulkan terbagi atas dua, yaitu data primer dan data sekunder. Data primer yaitu hasil wawancara dengan 24 informan yang sudah ditentukan oleh penulis untuk mendukung isi penelitian tesis dengan judul "Analisis Pemberdayaan kelompok Informasi Masyarakat (KIM) sebagai saluran berbagi informasi tentang penangkapan telur ikan terbang di Kabupaten Majene dan Kabupaten Polewali Mandar". Hasil wawancara tersebut,yaitu bertemu langsung dengan informan. Data sekunder, yaitu hasil kajian pustaka berupa penelusuran buku, jurnal ilmiah, majalah, skripsi, tesis, desertasi, internet ataupun sumber informasi lainnya yang dapat membantu melengkapi serta menunjang penelitian ini.

\section{Teknik Pengumpulan Data}

Dalam penelitian kualitatif, pengumpulan data dilakukan secara langsung di lokasi penelitian untuk memperoleh bahan, data dan informasi, sumber data primer, dan teknik pengumpulan data lebih banyak pada observasi, wawancara serta dokumentasi. Oleh karena itu peneliti melakukan pengumpulan data dengan cara, yaitu bertemu langsung dengan informan.

\section{HASIL PENELITIAN}

\section{Kelompok Informasi Masyarakat di dua kabupaten}

Daerah Kabupaten Majene telah terbentuk Kelompok Informasi Masyarakat sebanyak 15 KIM dan Kabupaten Polewali Mandar sebanyak 51 KIM yang tersebar dibeberapa Kecamatan, kelurahan atau desa dari sekian banyak jumlah kelompok yang terdaftar di instansi terkait mereka juga mempunyai berbagai ragam bidang aktivitas yang ditekuni para KIM tersebut sesuai Tabel 1. KIM yang terbentuk ini merupakan forum binaan dari Dinas Perhubungan Komunikasi dan Informatika, diharapkan mampu mewujudkan masyarakat yang aktif dan peka akan informasi. Serta menciptakan jaringan informasi media komunikasi khususnya ketika ada kebijakan pemerintah yang ingin disampaikan kepada masyarakat. KIM inilah dapat berperan langsung menyampaikannya dan KIM ini juga diharapkan menghubungkan satu kelompok masyarakat dengan kelompok lainnya agar bisa saling memberdayakan. Salah satunya dalam mengumpulkan, mengelola dan menyebarkan informasi guna menciptakan daerah yang mandiri akan mengakses informasi.

\section{Kelompok Informasi di Kelurahan Mosso Kabupaten Majene \\ Di Kecamatan Sendana tepatnya} Kelurahan Mosso terbentuk kelompok sosial yang bernama KIM "Turu' Cinna". KIM ini terbentuk salah satunya bertujuan untuk membantu pemerintah dalam menyampaikan informasi tentang berbagai kebijakan pemerintah daerah maupun pemerintah pusat 
agar lebih cepat sampai ke masyarakat sebaliknya KIM ini juga sebagai penyerap aspirasi dari masyarakat untuk disampaikan kepemerintah.KIM ini bergerak dibidang usaha perikanan dan anggotanya sebanyak 15 orang terdiri dari kalangan nelayan, mahasiswa dan pedagang.

\section{Kelompok Informasi di Desa Pambusuang Kabupaten Polewali Mandar}

KIM di Desa Pambusuang Kecamatan Balanipa Kabupaten Polewali Mandar diberi nama KIM "Kakanna".KIM ini bergerak dibidang pemberdayaan masyarakat pesisir dan pertunjukkan seni dan budaya selain dari itu KIM Kakanna juga sebagai wadah untuk peningkatan belajar mengajar melalui pusat kegiatan belajar mengajar (PKBM) dan sanggar theater (drama), anggotanya sebanyak 25 yang terdiri dari kalangan penggiat budaya dan pendidikan. KIM ini diharapkan dapat menciptakan jaringan informasi media komunikasi dua arah dengan menghubungkan satu kelompok masyarakat dengan kelompok lainnya agar bisa saling memberdayakan. Salah satunya dalam mengumpulkan, mengelola dan menyebarkan informasi guna menciptakan desa mandiri akan mengakses informasi.

\section{Budaya menangkap Telur Ikan terbang di Masyarakat Mandar}

Mandar ialah suatu kesatuan etnis yang berada di Sulawesi Barat. Dulunya, sebelum terjadi pemekaran wilayah, Mandar bersama dengan etnis Bugis, Makassar dan Toraja mewarnai keberagaman di Sulawesi Selatan. Meskipun secara politis Sulawesi Barat dan Sulawesi Selatan diberi sekat, secara historis dan kultural Mandar tetap terikat dengan "sepupu-sepupu" serumpunnya di Sulawesi Selatan.

Masyarakat Mandar memiliki mata pencarian sebagai nelayan. Melaut bagi suku Mandar merupakan sebuah penyatuan diri dengan laut. Rumpon atau roppong dalam bahasa Mandar adalah tehnologi penangkapan ikan yang pertama kali ditemukan oleh pelaut Mandar tetapi sekarang menggunakan balebale atau epe-epe untuk menangkap telur ikan terbang, perahu sandeq adalah perahu tradisional bercadik yang tercepat dan ramah lingkungan dikawasan Austronesia. Ide penciptanya berasal dari aral yang ditemukan pelaut Mandar dilaut. Mencari hidup dilaut bukanlah pekerjaan sembarangan bagi orang Mandar.

Upacara ritual berkenaan dengan laut dikenal dengan istilah makkuliwa dan maqappu merupakan dua ritual yang dipersiapkan untuk memberikan kekuatan psikologis kepada para nelayan agar tidak takut menghadapi segala kemungkinan yang ada di alam dalam menajalankan aktivitas mata pencaharian. Selain dari proses ritual tersebut masyarakat juga harus menentukan hari yang bagus dalam melakukan perjalanan.

\section{Peran dan Pemberdayaan KIM sebagai saluran berbagi informai dikalangan Nelayan}

KIM sangat berperan penting dalam menyampaikan langsung informasi kepada masyarakat dan KIM juga diharapkan dapat menghubungkan satu kelompok masyarakat dengan kelompok lainnya agar bisa saling memberdayakan. Salah satunya dalam mengumpulkan, mengelola dan menyebarkan informasi, selain dari pada itu KIM juga mempunyai fungsi sebagai lembaga yang memiliki nilai ekonomi yang dapat menciptakan daerah yang mandiri dan peka terhadap informasi. Pemerintah sebagai forum binaan KIM mempunyai salah satu tugas dan fungsi yaitu meningkatkan kualitas SDM KIM dalam mengelola informasi dengan mengadakan kegiatan-kegiatan yang bersifat pemberdayaan atau bagaimana pemerintah memberikan penguatan terhadap kelompok dari yang tidak mempunyai apa-apa menjadi sebuah kelompok yang mempunyai nilai lebih.

\section{PEMBAHASAN}

Penelitian ini menunjukkan bahwa peran KIM terutama di kalangan masyarakat nelayan sangat dibutuhkan, sebagaimana program yang telah dilakukan pemerintah dalam mendukung KIM untuk menjadikan masyarakat sadar akan informasi. Peranan merupakan dari pengertian sebagaimana membimbing dan sebagai seoarang yang berada disuatu kelompok atau organisasi, yang sifatnya memiliki peran opinion leader yang cukup bisa menggerakan anggotanya atau masyarakatnya. Soekanto (2001), mengatakan peranan adalah suatu konsep tetang apa yang dapat dilakukan oleh individu dalam masyarakat sebagai organisasi.

Dalam penelitian ini ditemukan KIM dalammenyebarkan informasi yang diterapkan 
di Kelurahan Mosso kurang maksimal begitupun juga dengan di Desa Pambusuang. Teori informasi sangat tepat digunakan dalam hal efisiensi dan akurasi suatu informasi agar tujuan atau isi pesan tersebut dapat diterima khalayak sesuai dengan apa yang diharapkan. Dalam teori yang dikembangkan Shannon et al (1949), masalah-masalah komunikasi disederhanakan dengan menggunakan pemikiran-pemikiran probabilitas (kemungkinan) agar dapat meminimalkan noise(gangguan) dalam berkomunikasi sehingga ketidakpastian dapat direduksi.

Program pemberdayaan KIM merupakan kegiatan atau strategi pemerintah dalam menguatkan serta mendukung kegiatankegiatan yang di lakukan KIM untuk mencapai tujuan yang telah ditetapkan, yaitu membantu membangun masyarakat madani yang informatif, komunikatif, aspiratif dan kreatif. Seperti yang dikatakan Siagian (1997), strategi adalah bahwa serangkaian keputusan dan tindakan mendasar yang dibuat oleh manajemen puncak dan diimplementasikan seluruh jajaran suatu organisasi dalam rangka pencapaian tujuan organisasi tersebut.

Output dari KIM ini diharapkan dapat menjadi KIM yang mandiri dan kreatif sehingga dapat menghasilkan inovasi-inovasi atau ide-ide baru dimana bisa memberikan efek positif kepada masyarakat banyak, sejalan dengan teori difusi inovasi dari Rogersdalam Cangara (2014), mengatakan bagaimana sebuah ide dan teknologi baru tersebar dalam sebuah kebudayaan, dan mendefinisikan difusi inovasi ialah dimana sebuah inovasi dikomunikasikan melalui berbagai saluran dan jangka waktu tertentu dalam sebuah sistem sosial.

Inovasi adalah suatu gagasan, praktek, atau benda yang dianggap/dirasa baru oleh individu atau kelompok masyarakat. Ungkapan dianggap/dirasa baru terhadap suatu ide, praktek atau benda oleh sebagian orang, belum tentu juga pada sebagian yang lain. Kesemuanya tergantung apa yang dirasakan oleh individu atau kelompok terhadap ide, praktek atau benda tersebut.

Peneliti juga menggunakan beberapa teori pendukung penelitian ini, seperti: teori informasi, teori groupthink dan teori difusi inovasi. Dalam teori groupthinkTurner (2008), mendefinisikan bahwa pemikiran kelompok (groupthink) sebagai suatu cara pertimbangan yang digunakan anggota kelompok ketika keinginan mereka akan kesepakatan melampaui motivasi mereka untuk menilai semua rencana tindakan yang ada. Jadi groupthinkmerupakan proses pengambilan keputusan yang terjadi pada kelompok yang sangat kohesif, dimanaanggota-anggota berusaha mempertahankan konsensus kelompok sehingga kemampuan kritisnya tidak efektif lagi. Teori ini menjadi salah satu rujukan yang digunakan dalam memberikan suatu gambaran bagaimana sebuah kelompok itu dibutuhkan kekompakan diantara anggotaanggota kelompok dalam mengambil suatu keputusan.

\section{KESIMPULAN DAN SARAN}

Berdasarkan hasil analisis dan hasil wawancara peneliti dengan beberapa informan mengenai proses peran kelompok informasi masyarakat dalam berbagi informasi tentang penangkapan telur ikan terbang dikalangan nelayan dan bentuk penyebaran informasi serta strategi pemerintah dalam pemberdayaan KIM, maka ditarik kesimpulan bahwa peran kelompok Informasi Masyarakat (KIM) dalam berbagi informasi dikalangan nelayan masih belum maksimal informasi yang mereka sebarkan hanya melalui media tatap muka atau komunikasi antar pribadi, belum memanfaatkan media apapun untuk penyebaran informasi tersebut, sehingga dalam meningkatkan kualitas SDM anggota kelompok Informasi Masyarakat dalam menyebarkan informasi dibutuhkan strategi pemberdayaan dari stakeholder seperti intitusi terkait Dinas Perhubungan Komunikasi dan Informatika Kabupaten Majene dan Polewali Mandar yang dapat bekerja sama dengan Dinas Kelutan dan perikanan Kabupaten Majene dan Polewali Mandar. Oleh karena itu beberapa saran yang diajukan peneliti adalah Pemerintah Daerah dan Pemerintah Desa hendaknya meningkatkan intensitas kualitas koordinasi dengan Kelompok Infomasi Masyarakat desa Pambusuang dan Kelurahan Mosso untuk mengontrol seberapa jauh KIM berjalan, dan terus mengontrol kegiatan kegiatan KIM.Pemerintah Daerah harus memperhatikan sarana dan prasarana penunjang kegiatan KIM dalam melaksanakan kegiatannya agar menjadi lebih baik dari sebelumnya. 


\section{DAFTAR PUSTAKA}

Ali S. A. (2005). Kondisi Sediaan dan Keragaman Populasi Ikan Terbang di Laut Flores dan Selat Makassar. Disertasi Pascasarjana Universitas Hasanuddin

Cangara H. (2014). Pengantar Ilmu Komunikasi. Edisi Kedua. Jakarta: Raja Grafindo Persada.

Departemen Komunikasi dan Informatika. (2008). Kerangka Acuan Arah Pengembangan dan pemberdayaan Kelompok Informasi Masyarakat (KIM). Jakarta: Departemen Komunikasi dan Informatika.

Moleong L. (2006). Metodologi Penelitian Kualitatif. Bandung: PT. Rosdakarya

Pelras C. (2006). Manusia Bugis. Jakarta: Nalar
Ruslan R. (2002). Manajemen Humas dan Manajemen Komunikasi. Jakarta: Raja Grafindo Persada

Shannon C. E. et. al. (1949). The Mathematical Theory of Communication. Urbana: University of Illionis Press

Siagiaan S. P. (1997). Teori Pengembangan Organisasi. Jakarta: Bumi Aksara.

Soekanto S. (2001). Sosiologi: Suatu Pengantar. Jakarta: Raja Grafindo Persada.

Turner W. (2008). Pengantar Teori Komunikasi Analisis dan Aplikasi. Jakarta: Salemba Humanika 
Table 1.Daftar Jumlah dan Nama Kelompok Informasi Masyarakat di 2 kabupaten

\begin{tabular}{|c|c|c|c|}
\hline $\begin{array}{c}\text { No. } \\
1 .\end{array}$ & $\begin{array}{l}\text { Kabupaten } \\
\text { Majene } \\
\text { (15) KIM }\end{array}$ & \multicolumn{2}{|c|}{ Nama KIM } \\
\hline 1. & $\begin{array}{l}\text { Majene } \\
\text { (15) KIM }\end{array}$ & $\begin{array}{ll}\text { 1. } & \text { Tunas Melati } \\
\text { 2. } & \text { Family } \\
\text { 3. } & \text { Kuda Laut } \\
\text { 4. } & \text { Hubrur Rasul } \\
\text { 5. } & \text { Bukit Harapan } \\
\text { 6. } & \text { Passawwang lawas } \\
\text { 7. } & \text { Mandiri } \\
\text { 8. } & \text { Anugrah }\end{array}$ & $\begin{array}{l}\text { 9. Tiga Serangkai } \\
\text { 10. Sinar Kabiraan } \\
\text { 11. Fajar Batu Sokko } \\
\text { 12. Turu' Cinna } \\
\text { 13. Pallulluareang } \\
\text { 14. Bunga Pelita } \\
\text { 15. Sejahtera }\end{array}$ \\
\hline 2. & $\begin{array}{l}\text { Polewali } \\
\text { Mandar } \\
\text { (51) KIM }\end{array}$ & $\begin{array}{l}\text { 1. Toeran Batu } \\
\text { 2. Rano Sipatangari } \\
\text { 3. Pantai Sappoang } \\
\text { 4. Gema Trikora } \\
\text { 5. Kuncup Mekar } \\
\text { 6. Sumber daya } \\
\text { 7. Karya Darma } \\
\text { 8. Bunga Mawar } \\
\text { 9. WiraKarya Indonesia } \\
\text { 10. Tadang Pali'e } \\
\text { 11. Taruna Mekar } \\
\text { 12. Mawar Mekar } \\
\text { 13. Karya Pattae } \\
\text { 14. Tunas Baru } \\
\text { 15. Samaturu } \\
\text { 16. Samusenga'na } \\
\text { 17. Harapan Baru } \\
\text { 18. Kadaro Mandar } \\
\text { 19. Pelita Raya } \\
\text { 20. Tomakaka } \\
\text { 21. KakaoMandar } \\
\text { 22. Tunas Harapan } \\
\text { 23. Trias Muda } \\
\text { 24. Sipakatau } \\
\text { 25. Mayapada } \\
\text { 26. Erlangga }\end{array}$ & $\begin{array}{l}\text { 27. Tunas Karya } \\
\text { 28. Washila } \\
\text { 29. Marendeng } \\
\text { 30. Sipakainga } \\
\text { 31. Paqbanua } \\
\text { 32. Samaturu } \\
\text { 33. Mandiri } \\
\text { 34. Mimmesa } \\
\text { 35. Balanipa } \\
\text { 36. Infak } \\
\text { 37. Tegar } \\
\text { 38. Hidayah } \\
\text { 39. Kakanna } \\
\text { 40. Paambimasa } \\
\text { 41. Allewuang } \\
\text { 42. Sipaingarang } \\
\text { 43. Siarioi Limboro } \\
\text { 44. Infak } \\
\text { 45. Bunga Coklat } \\
\text { 46. Allamungan Batu } \\
\text { 47. Talingarara } \\
\text { 48. Dimoamoa } \\
\text { 49. Sipatuo } \\
\text { 50. Siarioi Ambopadang } \\
\text { 51. Sipakainga }\end{array}$ \\
\hline
\end{tabular}

